\title{
Cross-cultural Pedagogy: Practical Strategies for a Successful Interprofessional Study Abroad Course
}

\begin{abstract}
Jieru Bai', Susan Larimer², and Mary Beth Riner ${ }^{3}$
Abstract: This article discusses some practical strategies for designing and implementing a cross-cultural interprofessional study abroad course, including pre-departure preparation, facilitating small groups with local students, establishing a weekly theme, utilizing role-play and reflective assignments, and implementing meaningful evaluation strategies. These strategies were based on three years of experience and were found to effectively increase students' cultural competence and self-confidence, as evidenced by student evaluations and results from a focus group conducted one year after the course. Short term study abroad courses with appropriate pedagogical design are significant strategies for health profession programs in the face of growing diversity and globalization.
\end{abstract}

Key words: cross-cultural, pedagogy, interprofessional, short term study abroad, health care, social work

Short term study abroad courses currently comprise over half of all study abroad courses in the U. S. (Institute for International Education, 2009). These experiences are becoming more common in social work as a way to increase students' cultural awareness and sensitivity. "To work effectively in any community, social workers require multicultural competencies grounded in an understanding of international issues and settings" (VeLure Roholt \& Fisher, 2013, p. 49). Recently there has been more evidence regarding the ability of study abroad courses to transform students' global perspectives, cross cultural effectiveness (Dwyer, 2004), professional identity (Moorhead, Boetto, \& Bell, 2014), and even produce an increased sense of self-confidence and self-reliance (Corda, 2007). VeLure Roholt and Fisher (2013) believed that just being abroad in a foreign locale is not enough to give students multicultural learning. The course pedagogy must be structured to allow students to reflect upon their learning and evaluate their assumptions. According to the National Association of Social Workers (NASW, 2001), cultural competence is a process by which individuals and systems respect and function effectively with people of

\footnotetext{
${ }^{1}$ Grace Abbott School of Social Work, University of Nebraska at Omaha, 6001 Dodge Street, Omaha, NE, 68182, bai@unomaha.edu.

${ }^{2}$ Indiana University School of Social Work, 902 West New York, Indianapolis, IN 46202, slarimer@iupui.edu.

${ }^{3}$ Indiana University School of Nursing, 600 Barnhill Drive, NU 118, Indianapolis, IN 46202,mriner@iu.edu
} 
all cultures and other diversity factors. Social work curricula in the United States can be enhanced by these short term study abroad courses.

For the past three years (2010-2012) our university and a Chinese university collaborated together on a six-week study abroad course focused on healthcare topics. The course was titled "China \& U.S. Health Care Issues: A Cross-Cultural Comparison." The original goal of the collaboration was for social work students to contrast healthcare services in two countries and to help the Chinese school understand medical social work, as social work is a new and developing profession in China. Later on, students from many other health-related disciplines joined and this course evolved into an interprofessional study abroad course.

This article will discuss some practical strategies for designing and implementing a cross-cultural interprofessional study abroad course. Several best practice strategies for short-term study abroad have been discussed in the literature including: 1) start with strong, clear academic content, 2) Make certain faculty are comfortable and competent with experiential teaching, 3) Ensure integration with the local community, 4) bring lecturers from the host country, and 5) Require ongoing reflection for both individual students and the group as a whole (Spencer \& Tuma, 2002). Our course used all five of these strategies as well as the following: 1) facilitating activities to increase cultural competence, 2) using faculty from multiple disciplines and broadening the course content to appeal to multiple disciplines, 3) and matching students from both countries together in groups for sustained interaction, and 4) using short and long-term evaluation practices. It is hoped that the lessons learned from this experience will be helpful for those undertaking interprofessional study abroad collaborations.

\section{Background of the Course}

In 2010, our university and a Chinese university signed a university level collaboration agreement. Based on this, many disciplines connected and developed collaboration programs. The Health Science Center (Medical School) of our partner university expressed a specific interest in medical social work. As a result, the School of Social Work at our university planned and implemented a study abroad course with the purpose to examine health care services in Beijing and make cross-cultural comparisons between the health care systems in China and the U.S.

After the initial success for social work students in the inaugural class in 2010, the Nursing School at our university joined the courses as well as students from public health and a few other health-related disciplines. Thus, this course evolved into a crosscultural, cross-university, and cross-disciplinary health care course. In order to better involve students from other disciplines, the focus of the course expanded from medical social work to psychosocial care in a broader sense. In the three-year history of the course, a total of 40 American students and 58 Chinese students have participated in our class. Students also visited nearly 20 different agencies related to health care in Beijing.

\section{Design}


When collaborating with a university in a foreign country, the communication between the partners in arranging the course activities is crucial to the success of the class. In this collaboration, each school had a clear role. The School of Social Work (SSW) of our university sent teachers and students, and were responsible for designing the course content and facilitating the classroom activities and discussions. We also had input into the decisions about the weekly topics and the visit locations. We interacted at each of visit sites with local hosts and facilitated discussion between U.S. students, Chinese students and host agencies. The Health Science Center (HSC) of our partner university was responsible for recruiting Chinese students who took this course as a non-credit class. More importantly, they arranged field trips and invited local speakers for selected healthcare topics. They also helped in all logistic issues, such as hotels, classrooms, and coach buses. The programs involved compensated them for the large amount of time that this effort required.

The student body of this class was composed of both undergraduate and graduate students. Most of them came from the schools of social work and nursing. There were also students from public health, sociology, biology, and anthropology. The three instructors were composed of two from social work and one from nursing. One of the social work instructors was native Chinese and played an important role in coordination and translation. It was very important that the instructors spend considerable time in course planning in order to ensure that interprofessional activities were developed that would help students understand their own as well as other disciplines.

The course was provided during a six week summer session. Adequate orientation was provided before traveling and students met for three intensive orientation sessions (6.5 hours each). After arriving in Beijing, the 3-week intensive course started. In the morning, students had lectures and discussions in the classrooms. In the afternoon, students visited hospitals and related social service agencies in Beijing.

Access to culturally competent translators is critical for this class because while all the Chinese students spoke some English, few of the agency personnel did. Almost all of the visits to local agencies required a translator. Due to the complication of medical terminology, Chinese students who had majored in medical English were hired to help in translation in addition to the bilingual instructor.

\section{Pedagogical Keys to Success}

The structure of study abroad courses varies greatly depending on the academic subject matter, the level of the students, and the nature of the subject being studied. The pedagogical strategies tried to transform all encounters a learning experience for the students. They not only learned from instructors, guest speakers, but also peers from multiple disciplines, service providers, as well as the whole environment. In this way, their cross-cultural learning experience was maximized in a short three-week period. The pedagogical strategies adopted in this course are as follows:

\section{Pre-departure preparation}


The three-day orientation covered basic Chinese language, culture, and general information about the health care systems in both China and the U.S. Manners and appropriate behavior while traveling abroad were discussed. Students had to sign an agreement on the expectations of the course while traveling abroad, such as punctuality and always traveling as a group. All the logistic details, such as food, housing, budget, packing, and safety, were discussed.

\section{Creating a sense of community}

Spencer and Tuma (2002) believed that a study abroad course should ensure integration with the local community. For this class, students stayed only in one city (Beijing) for three weeks. Because students had more intense exposure in one place, they developed a sense of safety and competence about their surroundings. Three weeks was found to be an ideal length of time for this short-term study abroad course. For most of the students, it was their first time to travel to China. Three weeks is long enough for them to have a sense of community but not too overwhelming for first-time traveling to China. In the past three years, we found a similar dynamic that students had an initial honeymoon phase with the culture in the first week, then began to experience some frustrations and homesickness in the second week, and then at the end of the trip, began to integrate their experiences and appreciate the learning they had accomplished.

\section{Diversity and small group interaction}

Diversity was the essential feature of this class. Students were from both undergraduate and graduate levels, different ethnicities (Chinese, Caucasian, African American, and Mexican), and different disciplines (social work, nursing, public health, psychology, sociology, biology, etc.). American students were paired with Chinese students and the small groups stayed together throughout the course. The cross-cultural interactions gave students a rich learning opportunity. In the classroom, they exchanged ideas about health care issues. Out of the classroom, they taught each other about informal cultural traits. Students were able to have formal and informal exchanges of cultural information all the time.

In the course evaluation, most students claimed that their favorite thing about this course was the interaction with students from other countries. One American student wrote in the course evaluation "One of the best things about this were our Chinese students. They were so nice, accommodating, and fun to be around". One Chinese student wrote "The interaction between the American students and the Chinese students was the biggest strength of the class, and the class would not have been the same without this element". Students from both countries continued connections with their small groups after the class.

\section{Establishing a weekly theme grounded in academic content}

In order to make health care relevant to students, we selected a specific topic for each week: cancer, mental health, and rural health. Students were able to relate to those 
common diseases that happen in people's everyday lives. Readings were given to the U.S. students about these topics before departure. Students were instructed to reflect on specific questions. For example, if you were diagnosed with cancer, what information would you want to know? What services do cancer patients need? What services do their families need? Can doctors and nurses take care of all the needs of patients and their families? In this way, students started with specific questions and gradually proceeded to deeper discussions.

For each topic, a Chinese expert was invited to introduce the state quo of specific healthcare issues in China. According to Spencer and Tuma (2002), bringing lecturers from the host country helps to establish a strong academic content and is a key to success for a study abroad course. Most of the guest speakers invited to this course spoke fluent English and had cross-cultural experiences in both China and the U.S. Thus they could engage both Chinese students and American students.

\section{Use of experiential activities}

Spencer and Tuma (2002) recommend that faculty leading the short-term study abroad course should be comfortable with experiential activities. For this course, experiential activities were used to engage students and demonstrate cultural difference. For example, we asked students to do a role play to present how patients go to the hospital in each country. Blatner (2009) posited that role playing is the best way to develop the skills of initiative, communication, problem-solving, self-awareness, and team work. Through role play, students had to relearn the health care systems in their own countries and found the best way to demonstrate it. The role play gave students vivid pictures about the cultural differences in health care in the two countries. The role play also showed students how a multi-disciplinary team works together to serve patients.

Many students wrote in their journals that the role play was very helpful for their learning. One student wrote:

"The role play was my favorite because we got to imitate the everyday basic conversation between a patient and a doctor. This was a great idea because it makes us understand the differences and similarities between both sides and actually see and have a feel of what it's like than hearing about it".

Another student wrote:

"I enjoyed the role-playing exercise this morning because it made the differences between the two systems more apparent and helped me to see how the patient, the family, and the medical staff were impacted in each scenario".

\section{Real world experiences---Field trips}

Learning through involvement is the most effective strategy for teaching students diversity and social justice (Jakubowski, 2003). This course provided students the opportunity to observe health care in the real world. Every afternoon, students visited hospitals and social service agencies in Beijing. They met doctors and social service professionals who shared their experiences of providing direct services. Students were able to see how psychosocial care was practiced in different cultures. One student wrote 
in the course evaluation:" The visits in the afternoon were helpful in understanding the week's topic and how it is addressed in China." Another student wrote:" It was also wonderful to see agencies that I would have never seen on a tourist visit to China."

\section{Reflective assignments}

Finn and Jacobson (2003) define critical reflection as "Systematically interpreting our individual and collective experiences, questioning taken-for-granted assumptions, and reframing our inquiry to open up new possibilities" (p. 176). Spencer and Tuma (2002) recommended ongoing reflection for both individual students and the group as a whole in order to deepen the learning. Students were required to continually reflect on their crosscultural experiencing by keeping daily journals during the course in Beijing. The journal was a place to write about ideas and questions generated from class discussion, agency visiting, and all other experiences. At the beginning of each day, students were expected to bring their journals to class and share with their group members. Then the instructors helped to facilitate critical reflections on the learning experiences from the previous day as a big group.

In order to help students organize their thoughts, we used the DEAL model to structure their reflections. The DEAL model is adapted from the work of Ash and Clayton (2004). It is an effective tool to help students structure their reflections. There are three parts in the DEAL model:

- Describe in detail your learning experience about health care in relation to the health care system, including the professional and folk systems, care patterns of individuals, families, and groups, how culture and social dimension factors influence care.

- Examine what is important about this experience (for example, cross-cultural comparisons of similarities and differences in behaviors, values, etc.) AND how you learned it.

- Articulate your Learning (AL) by describing why this matters and what you will do in light of this learning.

The DEAL model helped students compare the health care systems in specific dimensions so that they understood the underlying reasons for the similarity/differences between the two countries. Despite the focus on academic learning, we also provided students opportunities to reflect on their cross-cultural experiences in daily life. Once in a week, their reflection papers could be totally non-academic.

\section{Short-term and long-term evaluation}

Evaluation is critical to understanding the impact of the course and to inform future pedagogy. However, Witt, Bissonnette, and Power (2015) posited that a single time-point course evaluation has limited value for faculty attempting to gather feedback and redesign a course. For this course, evaluation was conducted both on the last day of the class and one year after the class. The short-term evaluation adopted the regular evaluation strategies. Students were surveyed on whether they achieved specific course objectives, how they rated professors, class formats and assignments, and whether they would recommend the class to other students. The long-term evaluation used a focus 
group one year after the class to gauge the long-term impact of the course. VeLure Roholt and Fisher (2013) stated that short-term study abroad courses must have a dual focus on delivering course content and supporting "perspective transformation" (p. 58). While the short-term evaluation measured students' academic learning, the long-term evaluation captured their personal growth.

\section{Impact of the Course}

The results of the short-term course evaluations indicated that more than $90 \%$ of the students felt they achieved the course objectives. The course helped students understand the different cultures and how cultures shape social services in the U.S. and China. More than $85 \%$ of the students believed that the combination of classroom study and agency visits enhances their learning. Almost all the students $(97 \%)$ would recommend this course to other students. In regarding to the aspects that facilitated students' learning, many students reported that their favorite activities were small groups with Chinese students (85\%) and agency visitations (57\%).

Along with the standard course evaluations, a focus group with the second year participants was conducted one year after the completion of the course. The focus group was approved by the Institutional Review Board of the university. Eight participants signed informed consents and reflected back on what was important about their experience and what it meant to them now. Two overriding themes stood out: increased cultural competence and increased personal confidence or sense of adventure.

\section{Increased cultural competence}

According to Abram and Cruce (2007), cultural competency is the "ability to respect cultural differences and shift to another cultural worldview" (p. 11). In the focus group, students demonstrated such abilities. Students talked about an enhanced awareness of their own culture and that of China. They were able to make comparisons between the two cultures and also see the commonalities between the two cultures. They talked about their appreciation for Chinese values, people, and hospitality. Students also reflected on the health care system and came to a realization that although there were some big differences, especially in how people were told about having a serious illness, they tried to understand and respect those differences.

One of the students said:

We were able to see how things could be different and get some really cool ideas about how to treat patients holistically and treating every part of them rather than just the disease. That revelation was just really pretty cool, and something that you know I think I want to be a part of, at least at some level in making some of those changes here and helping patients out in that way if possible.

Not only did students show increased cultural competence toward Chinese culture, but also increased cultural competence in a general sense. Students learned how to 
appreciate different perspectives and look at things through different lenses. Another students said:

"I think it really changed a lot of the people that I surround myself with, and not only that, some of the situations that I've been in...work, school, this, that and the other, I mean I just step back and actually think about other views than my own".

\section{Increased confidence}

Students experienced more than just cultural awareness and increased cultural competence by going to China. They felt that visiting the country and studying abroad gave them increased personal confidence about travel, and this confidence even transferred to other areas of their lives. Some students believed that studying abroad gave them confidence to try new things. This sense of adventure translated into being more adventurous about eating, using public transportation, and trying new activities.

One of the students said:

"Along the same lines of about being like "I can do it", I kind of thought about sky diving, but only in the abstract, like Oh yeah, that would be something cool to do, jump out of a plane, but it was only till we were in China and doing all these cool awesome things that we never dreamed we would ever do that we started talking about it, and you know a month later [after returning to the U.S.], we actually drove out there and were successful. ... and it was an awesome experience I never thought I would be able to do, and I did it, and I think it was definitely because of China."

Some other students believed that studying abroad helped them with selfawareness and interpersonal relationships. One student shared that

"I discovered that I could be independent, and I could just drop everything and go to China for three weeks, and that I could have a fun time without my significant other always there... I think if I hadn't gone to China, our relationship [with her husband] wouldn't be as good as it is now".

\section{Pedagogical Challenges and Recommendations}

Despite all the successful pedagogical strategies, we also encountered several challenges. Over the three years, we made numerous adjustments to overcome these challenges and evolve as the course transformed from a social work focus to an Interprofessional focus. However, there is still room for improvement.

The first challenge was that some American students lacked knowledge about their own health care system before they could compare it with the Chinese health care system. In 2010, American students were not prepared with such information. Some students reported that more background information about the health care system in their own country would strengthen the cross-cultural comparison. In order to address this, we invited local service providers to the orientations in 2011 and discussed healthcare issues in selected topic areas in the United States. In 2012, we took a further step. Students were 
organized to visit comparable hospitals and health care agencies in the United States before experiencing the ones in Beijing.

The second challenge was that the workload for the instructors was intense. Taking students abroad for three weeks meant huge responsibilities. The instructors not only had to teach classes, but also supervised the students on a 24/7 basis. The language barrier in China is significant. Students were more dependent upon the bilingual instructor for assistance with activities outside classroom. The bilingual instructor had to serve multiple roles, such as interpreter, culture broker, coordinator, and educator. Because of this dependence on the bilingual instructor, outsourcing the sightseeing to a local tourist company helped relieve the instructor burden in subsequent years. We recommend having an instructor to student ratio no higher than 1:7 when visiting China due to student dependence upon instructors.

Last but not least, the evaluation plan was not consistent because the instructors changed every year (except for the bilingual instructor). The course evaluation was developed by the instructors of the 2010 class and the later instructors made changes based on it. The focus group was only for 2011 students because their instructors decided to do so. In the future, it will be better to have consistent course evaluation for all students. Evaluations should also be obtained from instructors, field agencies, and administrators from the Chinese university. Furthermore, we recommend adopting established measurement on the key variables, such as cultural competence and selfconfidence.

\section{Conclusion}

This article shared the lessons learned from a cross-cultural interprofessional study abroad course that began as a social work course but evolved into an interdisciplinary course. Key pedagogical strategies that were offered included: integrating academic content on health care topics with community visits and engagement, using experiential teaching methods in the classroom to make the cultural connections come alive, promoting interdisciplinary dialogue and discussion, inviting speakers from the local community, requiring journaling and ongoing reflection to help students integrate their daily experiences, and using both short-term and long-term evaluation. The pedagogical strategies were found to be effective in increasing cross-cultural learning, as reflected in the course evaluations.

Meanwhile, this article shared the challenges encountered in three years and made recommendations for the future. It is hoped that the lessons learned from this experience will be helpful for those undertaking social work and interprofessional study abroad collaborations. In the face of globalization, social work students should have more crosscultural experiences in order to understand clients from different cultural backgrounds. Short term study abroad courses with appropriate pedagogical design will effectively enhance students' cultural competence. 


\section{References}

Abram, F.Y., \& Cruce, A. (2007). A reconceptualization of 'reverse mission' for international social work education and practice. Social Work Education, 26, 3-19.

Ash, S.L., \& Clayton, P.H. (2004). The articulated learning: An approach to guided reflection and assessment. Innovative Higher Education; 29, 137-154.

Blatner, A. (2009). Role plan in education. Retrieved September 2015, from http://www.blatner.com/adam/pdntbk/rlplayedu.htm

Corda, K.W. (2007). Reflections on a mini-mester abroad. Proceedings of the 2007

Commission on International Adult Education Pre-Conference (pp. 17-24). Norfolk: The Association of Adult and Continuing Education.

Dwyer, M. M. (2004). More is better: The impact of study abroad program duration.

Frontiers: The Interdisciplinary Journal of Study Abroad, 10, 151-163.

Finn, J., \& Jacobson, M. (2003). Just practice: A social justice approach to social work. Peosta, IA: Eddie Bowen Publishers.

Institute for International Education (2009). Open doors report on international education exchange. Retrieved from http://opendoors.iienetwork.org/

Jakubowski, L.M. (2003). Beyond book learning: Cultivating the pedagogy of experience through field trips. The Journal of Experiential Education, 26(1), 24-33.

Moorhead, B., Boetto, H., \& Bell, K. (2014). India and US: Student development of professional social work identity through a term study abroad program. Social Work Education, 33(4), 175-189.

National Association of Social Workers. (2001). NASW Standards for cultural competence in social work practice 2001. Retrieved September 2010, from http://www.naswdc.org/practice/standards/NASWCulturalStandards.pdf

Spencer, S.E., \& Tuma, K. (Eds.). (2002). The guide to successful short-term programs abroad. NAFSA: Association of International Educators.

Velure Roholt, R., \& Fisher, C. (2013). Expect the unexpected: International short-term study course pedagogies and practices. Journal of Social Work Education, 49(1), 48-65.

Witt, J., Bissonnette, C., \& Power, M.E. (2015). Student feedback from beginning to end: A new course evaluation model. Retrieved from

http://ir.lib.uwo.ca/wcse/WCSEFifteen/thur_july_9/19/ 